\title{
Irradiation-induced formation of a spinel phase at the $\mathrm{FeCr} / \mathrm{MgO}$ interface
}

Yun $\mathrm{Xu}^{1,2+}$, Satyesh Kumar Yadav $^{1+}$, Jeffery A. Aguiar ${ }^{1}$, Osman Anderoglu ${ }^{1}$, Jon Kevin Baldwin $^{3}$, Yongqiang Wang ${ }^{1}$, Amit Misra ${ }^{4}$, Hongmei Luo ${ }^{2}$, Blas P. Uberuaga ${ }^{1}, \mathrm{Nan} \mathrm{Li}^{3 *}$ 1 Materials Science and Technology Division, MST-8, Los Alamos National Laboratory, Los Alamos, New Mexico 87545, USA

2 Department of Chemical and Materials Engineering, New Mexico State University, Las Cruces, New Mexico 88003, USA

3 Materials Physics and Applications Division, MPA-CINT, Los Alamos National Laboratory, Los Alamos, New Mexico 87545, USA

4 Department of Materials Science and Engineering, University of Michigan, Ann Arbor, Michigan 48109, USA.

+ These authors contributed equally to this work

* Corresponding authors: N.L. E-mail: nanli@lanl.gov, tel: 505-665-1857.

\section{Abstract}

Oxide dispersion strengthened ferritic/martensitic alloys have attracted significant attention for their potential uses in future nuclear reactors and storage vessels, as the metal/oxide interfaces act as stable high-strength sinks for point defects while also dispersing helium. Here, in order to unravel the evolution and interplay of interface structure and chemistry upon irradiation in these types of materials, an atomically sharp $\mathrm{FeCr} / \mathrm{MgO}$ interface was synthesized at $500^{\circ} \mathrm{C}$ and separately annealed and irradiated with $\mathrm{Ni}^{3+}$ ions at $500^{\circ} \mathrm{C}$. After annealing, a slight enrichment of $\mathrm{Cr}$ atoms was observed at the interface, but no other structural changes were found. However, under irradiation, sufficient $\mathrm{Cr}$ diffuses across the interface into the $\mathrm{MgO}$ to form a Cr-enriched transition layer that contains spinel precipitates. First-principles calculations indicate that it is energetically favorable to incorporate $\mathrm{Cr}$, but not $\mathrm{Fe}$, substitutionally into $\mathrm{MgO}$. Our results indicate that irradiation can be used to form new phases and complexions at 
interfaces, which may have different radiation tolerance than the pristine structures.

\section{Introduction}

Metal/oxide interfaces have played a critical role in a variety of industrial fields with significant ramifications for structural composites, electroceramic devices, and environmental coatings especially with nuclear-energy applications[1-6]. The unique properties of such interfaces rely on the transition from the delocalized metallic bonding to ionic or covalent bonding in oxides. How the crystallography of metals orients with oxides and especially how the first metal layer bonds with the adjoining oxide layer at the interface will, to a large extent, determine the properties of the whole composite, and thus have become the focus of extensive study[1-6].

Because of commercial viability, high purity single-crystal $\mathrm{MgO}$ has been widely used as a model substrate to synthesize epitaxial metal films and to investigate the atomic configuration of heterointerfaces. Generally, when face centered cubic (fcc) metals are epitaxially grown on $\mathrm{MgO}(100)$, the preferred orientation relationship is (100) metal ॥ (100) $\mathrm{MgO} \&$ [001] metal ॥ [001] $\mathrm{MgO}$ (referred to here as OR-I) [7, 8]. The orientation relationship changes to (111) metal II (111) $\mathrm{MgO} \&$ [110] metal \| [110] MgO (OR-II) when metals are synthesized on $\mathrm{MgO}$ (111) substrates $[9,10]$. In both cases, fcc metals prefer to bind on top of oxygen. These features seem to be independent of the lattice mismatch between metals and $\mathrm{MgO}$, since the general relationship applies equally well for a variety of systems, such as $\mathrm{Ag} / \mathrm{MgO}(3 \%), \mathrm{Pd} / \mathrm{MgO}$ (7.6\%) and even $\mathrm{Cu} / \mathrm{MgO}(14.2 \%)$. In order to accommodate the lattice mismatch induced strain, misfit dislocations tend to dissociate into partials for these interfaces, in particular $1 / 2 \mathrm{a}_{\text {metal }}<100>$ for OR-I and $1 / 6 \mathrm{a}_{\text {metal }}<112>$ for OR-II $[11,12]$. Bollmann's O-lattice theory accurately predicts 
the interfacial misfit dislocation network [12, 13]. Atomic and electronic-structure calculations have explored the structural features in detail for the $\mathrm{Ag} / \mathrm{MgO}$ system: i) for the $\mathrm{MgO}$ surface, the most favorable adsorption site of Ag atoms changes depending on the coverage of the metal atoms on the surface $[14,15]$; ii) the distance between the first $\mathrm{Ag}$ plane and $\mathrm{MgO}$ surface is expanded with respect to both $\mathrm{Ag}$ and $\mathrm{MgO}$ (001) inter-planar distances [16].

The situation becomes more complicated when body centered cubic (bcc) metals are deposited on $\mathrm{MgO}$ substrates. Wang et al. uncovered the interface orientation relationship of single crystal Cr epitaxially grown on $\mathrm{MgO}$-- $\mathrm{Cr}$ (100) ॥ MgO (100) \& Cr [110] ॥ MgO [100] (OR-III) -- and they reported that the misfit dislocation spacing is less than the theoretical prediction [17]. Their experimental analysis revealed that $\mathrm{Cr}$ atoms reside on top of $\mathrm{O}$ atoms. First principle calculations [18] explored the preference of the bcc metals Fe, $\mathrm{Cr}$ and $\mathrm{V}$ on top of $\mathrm{O}$ atoms on the $\mathrm{MgO}$ (001) surface. However, Ikuhara et al. found that, for the interface structure of $\mathrm{V} / \mathrm{MgO}$, although the orientation relationship follows the same rule, the $\mathrm{V}$ atoms locate themselves directly on top of the $\mathrm{Mg}$ atoms $[19,20]$. Meanwhile, the distribution and Burgers vectors of misfit dislocations may be influenced by the interface morphology[21, 22]. In the $\mathrm{Nb} / \mathrm{MgO}$ system, due to interfacial faceting, the orientation relationship may change to $\mathrm{Nb}(110)$ $\|\mathrm{MgO}(100) \& \mathrm{Nb}[111]\| \mathrm{MgO}[011]$ (OR-IV) [21].

Recently, new applications of metal/oxide interfaces focusing on the enhancement of radiation tolerance, where the interfaces act as stable high-strength sinks for point defects by assisting the recombination process between interstitials and vacancies, have been reported [23]. Containing widely distributed nanosized oxide particles, oxide dispersion strengthened (ODS) ferritic/martensitic alloys exhibit high temperature creep strength[23] over traditional stainless steel. However, under irradiation, the elemental redistribution at boundaries or the change of 
oxide particles size commences[24-27], where the corresponding sink strength may be altered. Studying these complex ODS materials is rather difficult because of (i) the complex chemical composition of both matrix steels and oxide particles[28]; (ii) the challenge to probe the chemical composition of embedded three dimensional oxide nanoparticles (although atom-probe tomography (APT) has been widely applied to obtain 3D reconstructions of elemental components $[26,29,30]$, however, the extraction of quantitative chemical profiles around interfaces from APT is not straightforward); and (iii) the wide distribution of particle size[23]. Thus the use of model metal/oxide interfaces provides a route to uncover the fundamental behavior associated with the interfaces [31, 32]. Here, Fe 12 at.\% Cr has been epitaxially grown at $500{ }^{\circ} \mathrm{C}$ using single crystal $\mathrm{MgO}(100)$ as substrate. The resulting atomically sharp metal/oxide interface provides a clean reference to examine $\mathrm{Cr}$ solute redistribution and the ensuing structure/phase evolution under irradiation.

\section{Experimental methods}

The $100 \mathrm{~nm}$ FeCr layer was fabricated at $500{ }^{\circ} \mathrm{C}$ on $\mathrm{MgO}$ (100) substrate using cosputtering in a high vacuum chamber with a base pressure of $\leq 5.0 \times 10^{-8}$ torr. Two sources were used simultaneously with independent shutters and power supplies. The Fe power ran at 400 watts and the $\mathrm{Cr}$ power at 60 watts, in order to achieve approximate atomic ratios of $6.8 \mathrm{Fe}$ to 1 Cr. The deposition rate was approximately $0.4 \mathrm{~nm} / \mathrm{sec}$, with the total time of the deposition being 250 seconds. $10 \mathrm{MeV} \mathrm{Ni}^{3+}$ ions were utilized to irradiate the film at $500{ }^{\circ} \mathrm{C}$ to a fluence of $10^{16}$ ions $/ \mathrm{cm}^{2}$. The elapsed time of the irradiation, performed at the Ion Beam Materials Laboratory at Los Alamos National Laboratory (LANL), was $\sim 1$ hour. For comparison, a second assynthesized sample was annealed at $500{ }^{\circ} \mathrm{C}$ for 1 hour. The Monte Carlo simulation code Stopping and Range of Ions in Matter (SRIM) [33-35] was used (the displacement threshold 
energies used for all 4 species were $25 \mathrm{eV}$ while the calculations were performed in "quick" Kinchin and Pease mode) to determine the level of displacements per atom (dpa): $\sim 10$ dpa in the metal layer and $\sim 3 \mathrm{dpa}$ in the oxide layer (in the region near the interface). Analytical aberration corrected microscopy was performed on the image-corrected FEI Titan equipped with a Gatan Tridiem electron energy loss image filter (GIF) at LANL, operating in TEM mode at $300 \mathrm{keV}$. Scanning TEM (STEM) high angle annular dark field (HAADF) and electron energy-loss spectrometry (EELS) was performed using the probe-corrected FEI Titan operated at $300 \mathrm{keV}$ and $100 \mathrm{keV}$ Nion UltraSTEM at Oak Ridge National Laboratory.

\section{Results}

The microstructure of the as-deposited thin film is shown in Fig. 1. The cross-sectional TEM image (Fig. 1a) was taken in-zone. The dark lines in the FeCr film are threading misfit dislocations. The electron diffraction pattern in Fig. $1 \mathrm{~b}$ reveals that the $\mathrm{FeCr}$ film grown on the $\mathrm{MgO}$ substrate adopted a cube-on-cube relationship with a $45^{\circ}$ in-plane rotation: $\mathrm{MgO}$ (100) ॥ $\mathrm{FeCr}(200) \& \mathrm{MgO}$ [100] ॥ FeCr [110] (OR-III). The high resolution TEM image in Fig. 1c shows an atomically sharp interface. Observed along the $\mathrm{FeCr}[110]$ or $\mathrm{MgO}[100]$ direction, interfacial misfit dislocations can be identified as an extra atomic plane in the metal layer. All misfit dislocations reside at the interface with uneven spacing. The average spacing, measured by collecting multiple atomic resolution TEM micrographs at different locations (not all shown here), is $\sim 4.8 \mathrm{~nm}$, slightly larger than the theoretical prediction $(4.2 \mathrm{~nm})$. This may indicate that

the interfacial strain is not fully relaxed. A magnified image of one misfit dislocation is shown in Fig. 1d. The corresponding Burgers circuit (starting at $\mathrm{S}$ and ending at $\mathrm{F}$ ) has been drawn to identify the Burgers vector $\left(\mathbf{b}=1 / 2 \mathrm{a}_{\mathrm{FeCr}}[110]\right)$. Energy dispersive X-ray spectroscopy (EDS) line scans were performed normal to the interface to show the compositional variation for different 
chemical elements (in Fig. 1e). The profile of Cr presents a little bump but no interdiffusion at the interface region.

In order to better understand the thermal behavior of the system, in contrast to the irradiation-induced behavior discussed below, the synthesized sample was annealed for one hour at $500{ }^{\circ} \mathrm{C}$. After annealing, there is no observed structural change in either the $\mathrm{FeCr}$ or $\mathrm{MgO}$ layers. However, the EDS line scan in Fig. 2a shows obvious segregation of Cr towards the interface. For comparison, the $\mathrm{Cr}$ elemental EDS profiles of the synthesized and annealed samples have been overlapped and are presented in Fig. $2 \mathrm{~b}$. This result indicates that $\mathrm{Cr}$ is thermodynamically attracted to the interface, likely a consequence of the stronger interaction of Cr than Fe with oxygen.

The microstructure of the irradiated thin film is shown in Fig. 3a. Under heavy ion irradiation, a transition layer is formed on the $\mathrm{MgO}$ side of the $\mathrm{FeCr} / \mathrm{MgO}$ interface. The dark field high resolution STEM image of the irradiated interface shown in Fig. $3 b$ reveals that the thickness of the transition layer is $\sim 3.3 \mathrm{~nm}$, based on the stark difference in atomic contrast due to the presence of Cr. Irradiation effects on the thickness of transition layer will be evaluated in future work, which may be related to radiation-induced diffusion or ballistic impact. The majority of the transition layer has the same structure as $\mathrm{MgO}$. A magnified high resolution TEM micrograph presents an isolated misfit dislocation, with Burgers vector of $1 / 2 \mathrm{a}_{\mathrm{MgO}}$ [100], at the interface between $\mathrm{MgO}$ and the nucleated transition layer (as shown in Fig. 3c), indicating the periodic unit in the transition layer is close to, but smaller than, that in MgO. Magnified high resolution TEM image revealed that a certain region of the transition layer has the spinel structure, as indicated by the arrow and the inset of the atomic structure in Fig. 3d [36], and the corresponding thickness is $\sim 3 \mathrm{~nm}$ as well. Average EDS line profiles and 2-dimensional spectral 
imaging has been performed to quantify the chemical composition after irradiation (in Fig. 3e and 3f). Compared to the chemical profile of Fe, which shows no measurable intermixing across the interface, $\mathrm{Cr}$ diffused towards and segregated at the interface. The location of the $\mathrm{Cr}$ enrichment corresponds to the transition layer. Based on the integration of the peak profile, the stoichiometry ratio of $\mathrm{Mg}: \mathrm{Cr}$ is close to 1:2 in the transition layer. Further, the chemical valence of $\mathrm{Fe}, \mathrm{Cr}$ and $\mathrm{O}$ across the interface has been probed by atomically resolved EELS, as shown in Fig. 3g. After irradiation, the chromium content extends beyond the interface and builds up at the interface. In contrast to the slight enrichment on the metal side observed after annealing, after irradiation the $\mathrm{Cr}$ is on $\mathrm{MgO}$ side. The ionic valence state of chromium at the interface (calculated from the intensity ratio of $\mathrm{L}_{3} / \mathrm{L}_{2}$ at position 3 in Fig. $3 \mathrm{~g}$ ) is $3 \pm 0.1$ electrons, consistent with the presence of $\mathrm{Cr}^{3+}$ at the irradiated interface, suggesting that the spinelstructured precipitates are $\mathrm{MgCr}_{2} \mathrm{O}_{4}$ while the remainder of the transition layer is Cr-rich disordered rocksalt with a similar stoichiometry of $\mathrm{MgCr}_{2} \mathrm{O}_{4}$. With the current analysis, we cannot establish any relationship between the formation of $\mathrm{MgCr}_{2} \mathrm{O}_{4}$ spinel and the location of misfit dislocations. In situ irradiation could be used to correlate the formation of spinel with the structural features of the interface and will be performed in the future. We note that, under irradiation, spinels often transform to chemically identical and structurally related disordered rocksalt, in which the A and B cations are randomly distributed across the various cation sites in the rocksalt structure. Finally, a large number of defect clusters has been observed close to the interface in both materials, but no amorphous region has been observed either at the interface or inside $\mathrm{MgO}$ after irradiation, as expected from former studies [37-39].

\section{Discussion}

Exactly why chromium incorporates into $\mathrm{MgO}$ to form $\mathrm{MgCr}_{2} \mathrm{O}_{4}$, while iron does not is 
key to understanding the evolution of this particular metal/oxide interface. To provide insight into this question, density functional theory (DFT) calculations, using the Vienna Ab initio Simulation Package (VASP) [40], have been performed, in which the Perdew, Burke, and Ernzerhof (PBE) [41] generalized gradient approximation (GGA) exchange-correlation functional and the projector-augmented wave (PAW) method [42] have been employed. For all the calculations, a plane wave cutoff of $500 \mathrm{eV}$ for the plane wave expansion of the wave functions was used to obtain highly accurate forces. Because of the magnetic structure of $\mathrm{Cr}$ and $\mathrm{Fe}$, spin polarized calculations were considered for all cases. Force tolerance for the structural relaxation was $0.05 \mathrm{eV} / \mathrm{A}$. Disordered rocksalt was simulated by creating a special quasirandom structure (SQS)[43] with the rocksalt structure, but with the $\mathrm{MgCr}_{2} \mathrm{O}_{4}$ stoichiometry by replacing $3 \mathrm{Mg}$ ions with $2 \mathrm{Cr}$ ions for every structural unit of $4 \mathrm{MgO}$, as shown in Fig. 4 (a) and 4 (b).

Spinel $\mathrm{MgCr}_{2} \mathrm{O}_{4}$ is thermodynamically the most stable phase among all combinations of $\mathrm{Mg}, \mathrm{Cr}$ and $\mathrm{O}$. However, compared to a disordered rocksalt structure, in which the material has the spinel stoichiometry, but the $\mathrm{Mg}$ and $\mathrm{Cr}$ cations are randomly distributed in a rocksalt structure, the spinel structure is more stable only by $0.20 \mathrm{eV}$ per atom. Hence, during irradiation the intermixing of $\mathrm{Cr}$ into $\mathrm{MgO}$ and the formation of disordered rockstalt is possible before the atomic structure of the transition layer settles into the spinel structure (indeed, irradiation causes an order-to-disorder transformation of spinel into rocksalt [44]). Further, the DFT-calculated volume changes, compared to pristine $\mathrm{MgO}$, is $-1.9 \%$ and $-3.1 \%$ for disordered-rocksaltstructured and spinel-structured $\mathrm{MgCr}_{2} \mathrm{O}_{4}$, respectively, consistent with the experimental observations that the transition layer has a smaller lattice constant than the $\mathrm{MgO}$ substrate. These results suggest that a two-phase transition layer, containing both spinel and disordered rocksalt, is thermodynamically and structurally reasonable. 
The transition layer observed contains chromium not iron. This indicates that, upon incorporation into $\mathrm{MgO}, \mathrm{Cr}$ substitutes for $\mathrm{Mg}$ to form either rocksalt or spinel, but $\mathrm{Fe}$ does not. To model this process we inserted either one $\mathrm{Cr}$ or Fe atom into a 64-atom $\mathrm{MgO}$ supercell. The Fe or $\mathrm{Cr}$ atom is introduced in either a substitutional or interstitial position (the interstitial position is surrounded by $4 \mathrm{Mg}$ and $4 \mathrm{O}$ atoms [45]). In the substitutional case, the replaced $\mathrm{Mg}$ atom was placed in an interstitial position. Structures 1 and 2 in Fig. 4 (c) show both the interstitial and substitutional positions, respectively, of $\mathrm{Cr}$ or Fe defects within a $\mathrm{MgO}$ supercell. Structure 3 in Fig. 4 (c) represents Mg farther away from substituted ion as compared to structure 2.

For all structures we calculate the formation energy of both neutral and charged defects. The relative stability of different charge states is compared using the total energy of the system, which is given by $E^{\text {Total }}\left(D^{q}\right)=E_{f}^{D F T}\left(D^{q}\right)+q E_{F}$, where $E^{\text {Total }}\left(D^{q}\right)$ is the total energy of the system containing a $\mathrm{Cr}$ or $\mathrm{Fe}$ atom as defect interstitial or substitutional in charge state $\mathrm{q}$ and $E_{f}^{D F T}\left(D^{q}\right)$ is the DFT energy of the charged supercell. More details on the total energy calculations can be found in Janotti et al. [46]. The total energy of the neutral system does not depend on the charge state, while that of a charged supercell depends on the Fermi level $\mathrm{E}_{\mathrm{F}}$ of the electron reservoir referenced to the valence-band maximum (VBM) (in this case $\mathrm{FeCr}$ ). Even for the highest value of $\mathrm{E}_{\mathrm{F}}$, which is the bandgap of $\mathrm{MgO}(7.8 \mathrm{eV}$ as calculated with DFT), $\mathrm{Cr}$ and $\mathrm{Fe}$ in $\mathrm{MgO}$ are more stable in the 3+ charge state as compared to the neutral state. This type of replacement is consistent with other studies of $3+$ aliovalent doping of $\mathrm{MgO}$ [47].

In the $3+$ charge state, $\mathrm{Cr}$ prefers to be in a substitutional as compared to an interstitial 
position, as indicated in Fig. 4 (d). That is, the reaction $\mathrm{Cr}_{\mathrm{I}}^{3+} \rightarrow \mathrm{Cr}_{\mathrm{Mg}}{ }^{1+}+\mathrm{Mg}_{\mathrm{I}}{ }^{2+}$ is exothermic; it is favorable for a $\mathrm{Cr}$ interstitial to kick-out a $\mathrm{Mg}$ ion, forming a substitutional $\mathrm{Cr}$ and interstitial $\mathrm{Mg}$. Once $\mathrm{Mg}$ is knocked out of its lattice position, it will tend to migrate away from the substitutional $\mathrm{Cr}$ due to the electrostatic repulsion between $\mathrm{Mg}_{\mathrm{I}}{ }^{2+}$ and $\mathrm{Cr}_{\mathrm{Mg}}{ }^{1+}$. Thus, if $\mathrm{Cr}$ is knocked into $\mathrm{MgO}$ as an interstitial species during the collision cascade events, it will quickly displace sufficient $\mathrm{Mg}$ ions from the lattice, forming $\mathrm{MgCr}_{2} \mathrm{O}_{4}$. This is compatible with our HRTEM and EELS observations. On the other hand, the reaction $\mathrm{Fe}_{\mathrm{I}}^{3+} \rightarrow \mathrm{Fe}_{\mathrm{Mg}}{ }^{1+}+\mathrm{Mg}_{\mathrm{I}}^{2+}$ is endothermic, see Fig. 4 (d). Hence, even if Fe atoms are displaced into $\mathrm{MgO}$ and find a preexisting $\mathrm{Mg}$ vacancy, any residual $\mathrm{Mg}$ interstitials will displace that $\mathrm{Fe}$ back into an interstitial position, where they may diffuse back to the metal layer. This difference explains why $\mathrm{Cr}$ incorporation into $\mathrm{MgO}$ leads to the formation of spinel-like compounds, but the same does not happen when Fe is introduced into $\mathrm{MgO}$.

Together, the experimental and modeling results lead to the following picture for the chemical and structural evolution of the interfacial region under irradiation. By virtue of stronger binding with either oxygen or irradiation-induced point defects compared to $\mathrm{Fe}, \mathrm{Cr}$ atoms prefer to segregate towards the $\mathrm{FeCr} / \mathrm{MgO}$ interface under either annealing or irradiation [48-50]. With a layer of enriched $\mathrm{Cr}$ initially formed at the interface, the $\mathrm{Cr}$ atoms are then introduced randomly, either by radiation-enhanced diffusion or ballistic impact, into the $\mathrm{MgO}$ substrate. Fe will also be introduced into $\mathrm{MgO}$ via ballistic mixing. However, the $\mathrm{Cr}$ will substitute into the $\mathrm{MgO}$ structure while Fe will remain as an interstitial species and free to diffuse through the lattice. The inceptive ordering of the resulting $\mathrm{Cr}-\mathrm{Mg}-\mathrm{O}$ phase may be random, consistent with a rocksalt-structured compound. If kinetics allow, the chemistry may order and a spinel compound will eventually precipitate within the transition layer. Further, the propensity for disordering [51- 
56] depends on the stoichiometry of the spinel, with non-stoichiometric spinels more prone to disorder[52]. Accordingly, in our experiments, depending on the level of $\mathrm{Cr}$ substitution, the driving force for ordering into the spinel structure will be different. Thus, we have competing effects for determining the ultimate structure of the $\mathrm{Cr}$-substituted $\mathrm{MgO}$ transition layer. On the one hand, the kinetics associated with irradiation will disrupt the reordering process, driving the system towards the rocksalt structure, while, on the other hand, thermodynamics would drive this chemistry towards spinel. Combining the observations from the experiments and the DFT calculations, we conclude that $\mathrm{Cr}$ introduction into $\mathrm{MgO}$ leads to a transition layer that contains substitutional $\mathrm{Cr}$ ions, which, if the local conditions are conducive, can form $\mathrm{MgCr}_{2} \mathrm{O}_{4}$ spinel.

\section{Summary}

Fe-12at.Cr thin films were epitaxially grown on a single crystal MgO (100) substrate. The interface exhibited an orientation relationship of $\mathrm{MgO}(100) \| \mathrm{FeCr}(100)$ \& $\mathrm{MgO}$ [100] ॥ FeCr [110]. Misfit dislocations, with an average spacing of $4.8 \mathrm{~nm}$, were formed at the interface to mitigate the lattice mismatch strain. $10 \mathrm{MeV} \mathrm{Ni}^{3+}$ ion irradiation was performed at $500{ }^{\circ} \mathrm{C}$ to examine the structural and chemical stability of the interface while concurrent anneals of the assynthesized material were performed to separate the effects of irradiation. $\mathrm{Cr}$ was probed to segregate to the interface thermodynamically. Radiation-induced segregation of $\mathrm{Cr}$ from the $\mathrm{Fe}$ layer to and across the $\mathrm{FeCr} / \mathrm{MgO}$ interface was observed. As a result, a two-phase transition layer containing precipitates of a spinel phase along with Cr-rich rocksalt was formed on the $\mathrm{MgO}$ side of the $\mathrm{FeCr} / \mathrm{MgO}$ interface. First-principles calculations show that it is exothermic for interstitial $\mathrm{Cr}$ to substitute $\mathrm{Mg}$ in $\mathrm{MgO}$, but that $\mathrm{Fe}$ prefers to remain as an interstitial. The elemental redistribution and structural reordering we have observed at the $\mathrm{FeCr} / \mathrm{MgO}$ interface has implications beyond our study. Each of these changes in structure and chemistry can either 
enhance or degrade material performance and suggest that the properties of pristine materials are not representative of the structures that evolve under irradiation in complex composites. Thus, the interface morphologies in materials such as ODS that are responsible for the interaction with radiation-induced defects may be very different from the as-synthesized interfaces. Finally, this model study suggests irradiation can be used to form new phases and complexions at interfaces that may have new mechanical and functional properties[57, 58].

\section{Acknowledgements}

We gratefully acknowledge the support of the U.S. Department of Energy through the Los Alamos National Laboratory (LANL) / Laboratory Directed Research \& Development (LDRD) Program for this work. This research used resources provided by the LANL Institutional Computing Program. This work was performed, in part, at the Center for Integrated Nanotechnologies, an Office of Science User Facility operated for the U.S. Department of Energy (DOE) Office of Science. LANL, an affirmative action/equal opportunity employer, is operated by Los Alamos National Security, LLC, for the National Nuclear Security Administration of the U.S. Department of Energy under contract DE-AC52-06NA25396. JAA acknowledges access to the ORNL's ShaRE User Facility where part of the TEM work was performed in collaboration with Miaofang Chi and Juan Carlos Idrobo, which are sponsored by the Scientific User Facilities Division, Office of Basic Energy Sciences, U. S. Department of Energy. Y.Xu and H. Luo are affiliates supported by the New Mexico Consortium at LANL. 


\section{Figures}

Figure 1. Microstructure of and chemical distribution at the pristine $\mathrm{FeCr} / \mathrm{MgO}$ interface. (a) Bright field cross-sectional TEM image of $\mathrm{FeCr} / \mathrm{MgO}$ interface. (b) Corresponding electron diffraction pattern. (c) High resolution TEM image of the interface. (d) Magnified image of the interface, highlighting the structure of the misfit dislocation. (e) EDS profile of $\mathrm{Fe}, \mathrm{Mg}$ and $\mathrm{Cr}$ across the as-grown interface.

Figure 2. Chemical analysis of the $\mathrm{FeCr} / \mathrm{MgO}$ interface. (a) EDS composition profiles show the diffusion of $\mathrm{Cr}$ towards the interface after annealing. (b) Overlapping of the $\mathrm{Cr}$ profiles of pristine and annealed samples at the interface.

Figure 3. Microstructure of and chemical distribution at the irradiated $\mathrm{FeCr} / \mathrm{MgO}$ interface. (a) Bright field cross-sectional TEM image of the irradiated $\mathrm{FeCr} / \mathrm{MgO}$ interface with SRIM profile superimposed. (b) Dark field high resolution STEM image of the irradiated interface revealing the thickness of the transition layer is $\sim 3.3 \mathrm{~nm}$. (c) High resolution TEM image to characterize the structure of the misfit dislocation between the transition layer and the $\mathrm{MgO}$ substrate. (d) High resolution TEM micrograph identifying the structure of the transition layer and small regions with the spinel structure, as indicated by the arrow. The inset shows an atomic model of the structure of these regions, containing both $\mathrm{MgO}$ and spinel. (e) EDS line and (f) twodimensional mapping of $\mathrm{Fe}, \mathrm{Mg}$ and $\mathrm{Cr}$ across the irradiated interface. (g) EELS line scans performed at five different locations parallel to the $\mathrm{FeCr} / \mathrm{MgO}$ interface, as indicated in (e), reveal the valence state of $\mathrm{Cr}$ at the interface.

Figure 4. (a) $\mathrm{MgO}$ in rocksalt crystal structure and (b) $\mathrm{MgCr}_{2} \mathrm{O}_{4}$ with $3 \mathrm{Mg}$ replaced by $2 \mathrm{Cr}$, forming defective rocksalt structure. (c) Atomic structures of supercells containing $\mathrm{Cr}$ or $\mathrm{Fe}$ defects and the relative energy of various structures. The structures represent: (1) $\mathrm{Cr}$ or $\mathrm{Fe}$ at an 
interstitial position, (2) and (3) $\mathrm{Cr}$ or $\mathrm{Fe}$ at substitutional position and $\mathrm{Mg}$ at an interstitial position with increasing distance from the $\mathrm{Cr}$ or $\mathrm{Fe}$ substitutional atom, (d) corresponding relative formation energy.

\section{References:}

[1] Finnis MW. J. Phys.: Condens. Matter 1996;8:5811.

[2] Ernest F. Materials Science and Engineering 1995;R14:97.

[3] Nicholas MG, Mortimer DA. Mater Sci Technol 1985;1:657.

[4] Ruhle M, Evans AG. Mater Sci Eng A 1989;107:187.

[5] Sinnott SB, Dickey EC. Mater Sci Eng: R 2003;43:1.

[6] Howe JM. Int Mater Rev 1993;38:233.

[7] Bialas H, Heneka K. Vacuum 1994;45:79.

[8] Schonberger U, Andersen OK, Methfessel M. Acta Metall Mater 1992;40:S1.

[9] Lu P, Cosandey F. Ultramicroscopy 1992;40:271.

[10] Lu P, Cosandey F. Acta Metall Mater 1992;40:S259.

[11] Trampert A, Ernst F, Flynn CP, Fischmeister HF, Ruhle M. Acta Metall Mater 1992;40:S227.

[12] Chen FR, Chiou SK, Chang L, Hong CS. Ultramicroscopy 1994;54:179.

[13] Shashkov DA, Chisholm MF, Seidman DN. Acta Mater 1999;47:3939.

[14] Zhukovskii YF, Kotomin EA, Jacobs PWM, Stoneham AM, Harding JH. Surf Sci 1999;441:373.

[15] Heifets E, Zhukovskii YF, Kotomin EA, Causa M. Chem Phys Lett 1998;283:395.

[16] Giovanardi C, Bona Ad, Moia TS, Valeri S, Pisani C, Sgroi M, Busso M. Surf Sci 2002;505:L209.

[17] Wang C-M, Kaspar TC, Shutthanandan V, Joly AG, Kurtz RJ. Acta Mater 2011;59:4274.

[18] Tanaka I, Mizuno M, NakaJyo S, Adachi H. Acta Mater 1998;46:6511.

[19] Ikuhara Y, Sugawara Y, Tanaka I, Pirouz P. Interface Sci 1997;5:5.

[20] Ikuhara Y, Pirouz P, Yadavalli S, Flynn CP. Philos Mag A 1995;72:179.

[21] Li DX, Pirouz P, Heuer AH, Yadavalli S, Flynn CP. Acta Metall Mater 1992;40:S237.

[22] Fu EG, Fang Y, Zhuo MJ, Zheng SJ, Bi ZX, Wang YQ, Tang M, Ding X, Han WZ, Luo HM, Baldwin JK, Misra A, Nastasi M. Acta Mater 2014;64:100.

[23] Odette GR, Alinger MJ, Wirth BD. Annu Rev Mater Res 2008;38:471.

[24] Certain AG, Field KG, Allen TR, Miller MK, Bentley J, Busby JT. J Nucl Mater 2010;407:2.

[25] Allen TR, Gan J, Cole JI, Miller MK, Busby JT, Shutthanandan S, Thevuthasan S. J Nucl Mater 2008;375:26.

[26] Marquis EA, Lozano-Perez S, Castro Vd. J Nucl Mater 2011;417:257.

[27] Williams CA, Hyde JM, Smith GDW, Marquis EA. J Nucl Mater 2011;412:100.

[28] Bhattacharyya D, Dickerson P, Odette GR, Maloy SA, Misra A, Nastasi MA. Philoso Mag 2012;92:2089.

[29] Marquis EA, Hyde JM, Saxey DW, Lozano-Perez S, de Castro V, Hudson D, Willaime CA, Humphry-Baker S, Smith GDW. Mater Today 2009;12:30.

[30] Marquis EA. Appl Phys Lett 2008;93)181904. 
[31] Chen Y, Jiao L, Sun C, Song M, Yu KY, Liu Y, Kirk M, Li M, Wang H, Zhang X. J Nucl Mater 2014;452:321.

[32] Xu Y, Aguiar JA, Yadav SK, Anderoglu O, Baldwin JK, Wang YQ, Valdez JA, Misra A, Luo HM, Uberuaga BP, Li N. Acta Mater 2015;89:364.

[33] Stoller RE, Toloczko MB, Was GS, Certain AG, Dwaraknath S, Garner FA. Nucl Instru Methods Phys Res Sect B 2013;310:75.

[34] Ziegler JF, Ziegler MD, Biersack JP. Nucl Instru Methods Phys Res Sect B 2010;268:1818.

[35] http://www.srim.org.

[36] Sieber H, Hess D, Werner P. Philos Mag A 1997;75:889.

[37] White CW, McHargue CJ, Sklad PS, Boatner LA, Farlow GC. Materials Science Reports 1989;4:41.

[38] Sonoda T, Abe H, Kinoshita C, Naramoto H. Nucl Instru Methods Phys Res Sect B 1997;127/128:176.

[39] Jiao L, Chen A, Myers MT, General MJ, Shao L, Zhang X, Wang H. J Nucl Mater 2013;434:217.

[40] Kresse G, Furthmuller J. Phys Rev B 1996;54:11169.

[41] Perdew JP, Burke K, Ernzerhof M. Phys Rev Lett 1996;77:3865.

[42] Blochl PE. Phys Rev B 1994;50:17953.

[43] Zunger A, Wei SH, Ferreira LG, Bernard JE. Phys Rev Lett 1990;65:353.

[44] Ishimaru M, Afanasyev-Charkin IV, Sickafus KE. Appl Phys Lett 2000;76:2556.

[45] Brudevoll T, Kotomin EA, Christensen NE. Phys Rev B 1996;53:7731.

[46] Janotti A, Varley JB, Rinke P, Umezawa N, Kresse G, Van de Walle CG. Phys Rev B 2010;81:085212.

[47] Prada S, Giordano L, Pacchioni G. J Phys Chem C 2012;116:5781.

[48] Was G, Wirth BD. Award Number: DE-FC07-07ID14828 2011.

[49] Was GS, Wharry JP, Frisbie B, Wirth BD, Morgan D, Tucker JD, Allen TR. J Nucl Mater 2011;411:41.

[50] Wharry JP, Jiao Z, Was GS. J Nucl Mater 2012;425:117.

[51] Sickafus KE, Larson AC, Yu N, Nastasi M, Hollenberg GW, Garner FA, Bradt RC. J Nucl Mater 1995;219:128.

[52] Sickafus KE, Yu N, Nastasi M. Nucl Instrum Methods Phys Res Sect. B 1996;116:85.

[53] Kinoshita C, Matsumura S, Yasuda K, Soeda T, Moujima M. Mat Res Soc Symp Proc 1999;540:287.

[54] Sickafus KE. Science 2000;289:748.

[55] Devanathan R, Sickafus KE, Yu N, Nastasi M. Philos Mag Lett 2006;72:155.

[56] Yu N, Sickafus KE, Nastasi M. Philos Mag Lett 2006;70:235.

[57] Harmer MP. Science 2011;332:182.

[58] Lu F, Lang M, Huang M, Namavar F, Trautmann C, Ewing RC, Lian J. Nucl Instrum Methods Phys Res Sect. B 2012;286:266. 
Figure 1
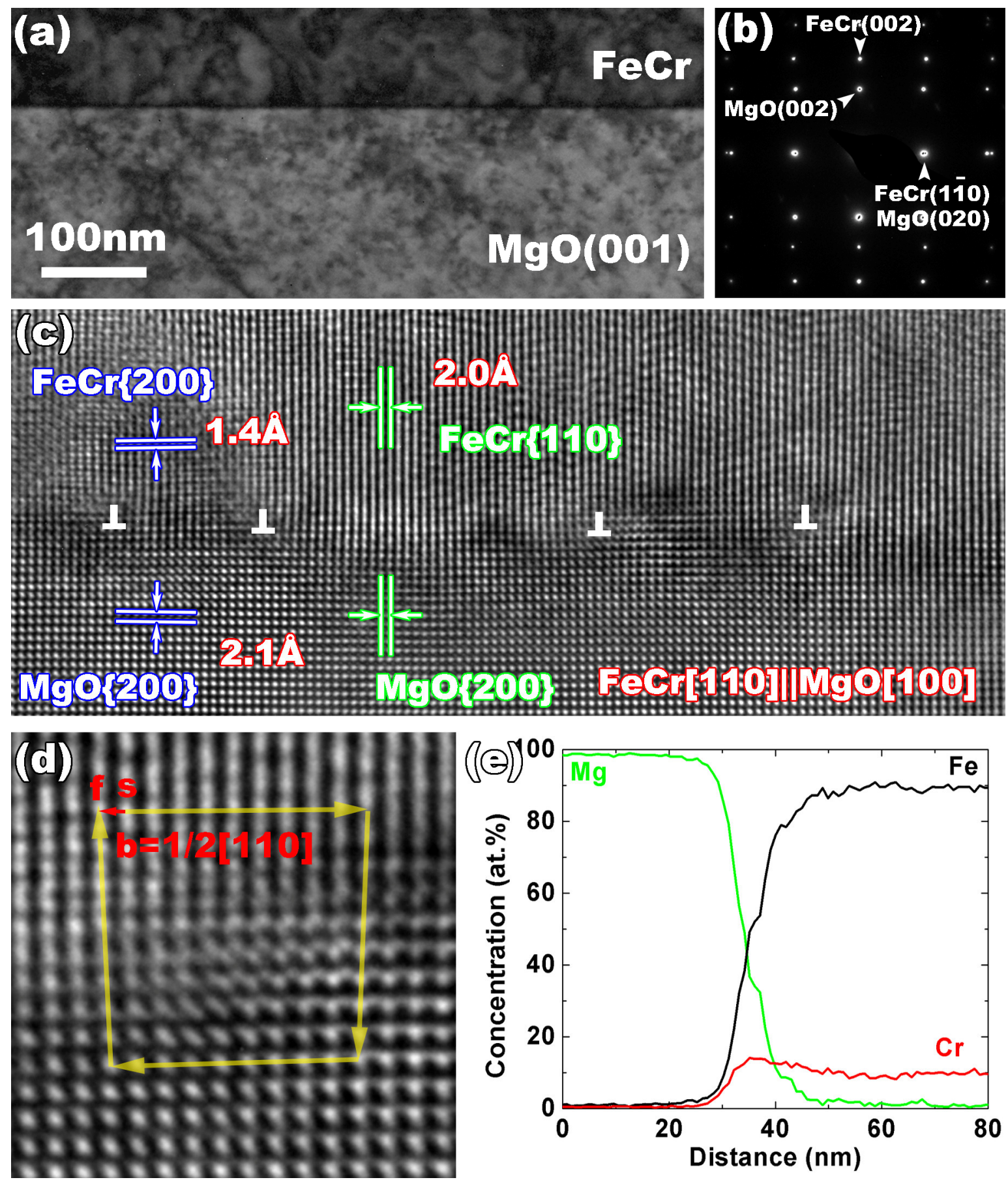
Figure 2
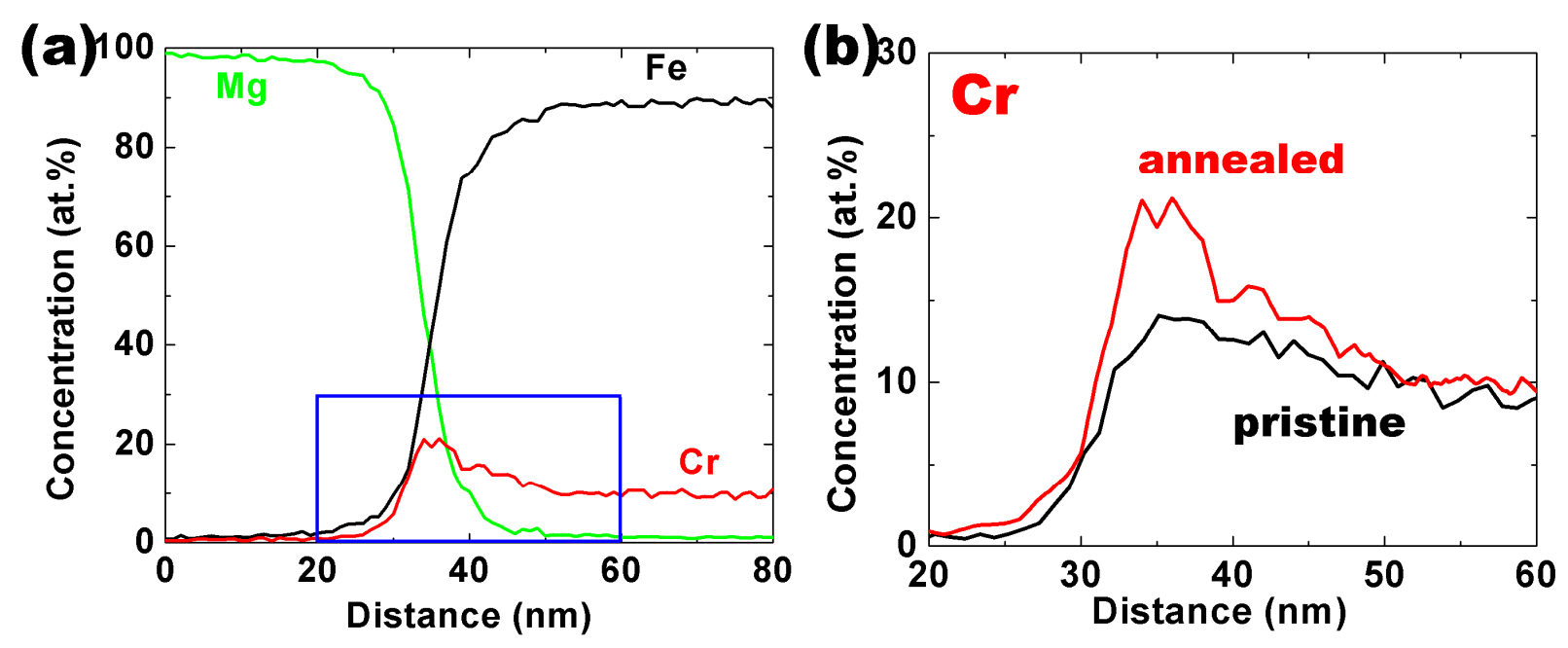
Figure 3
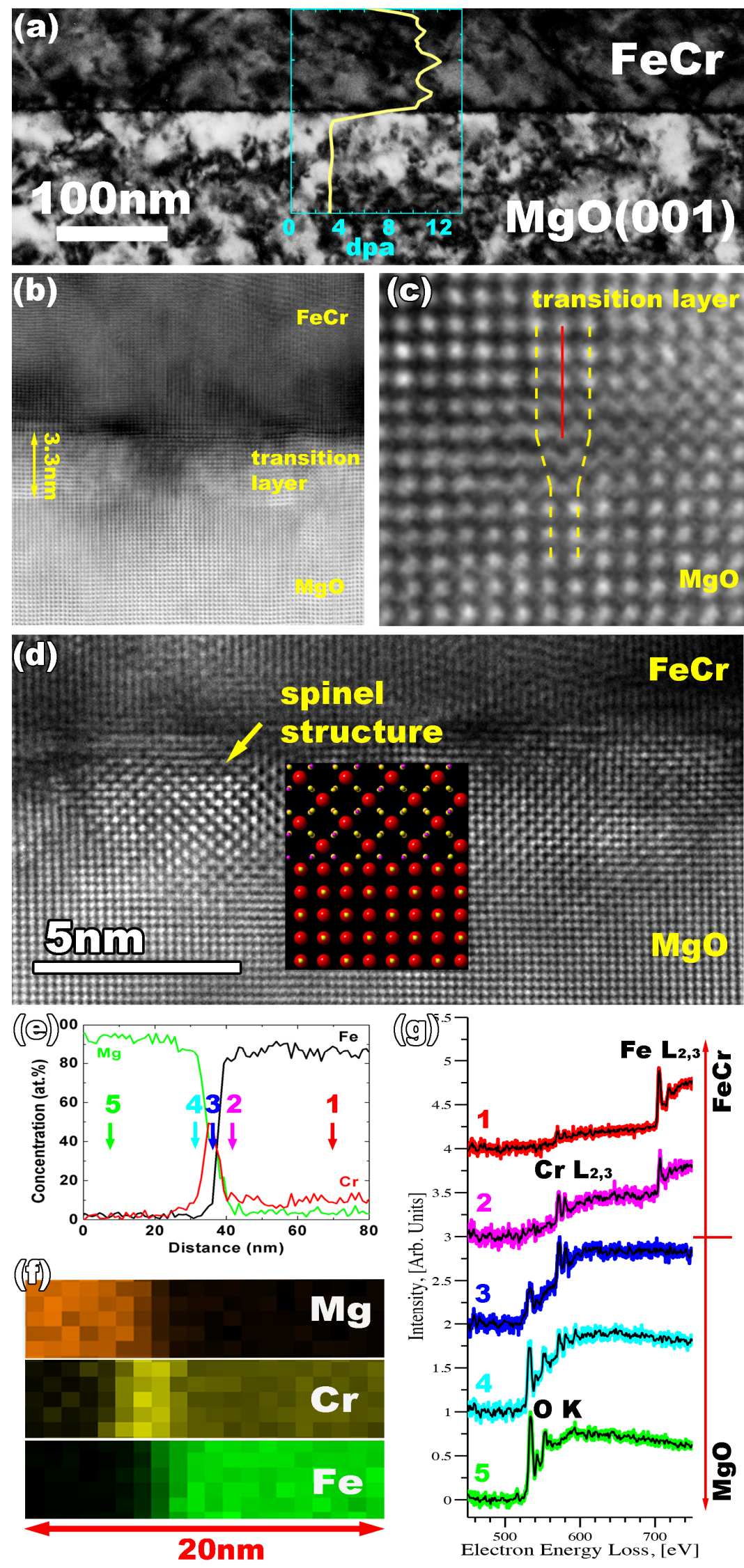
Figure 4

(a)
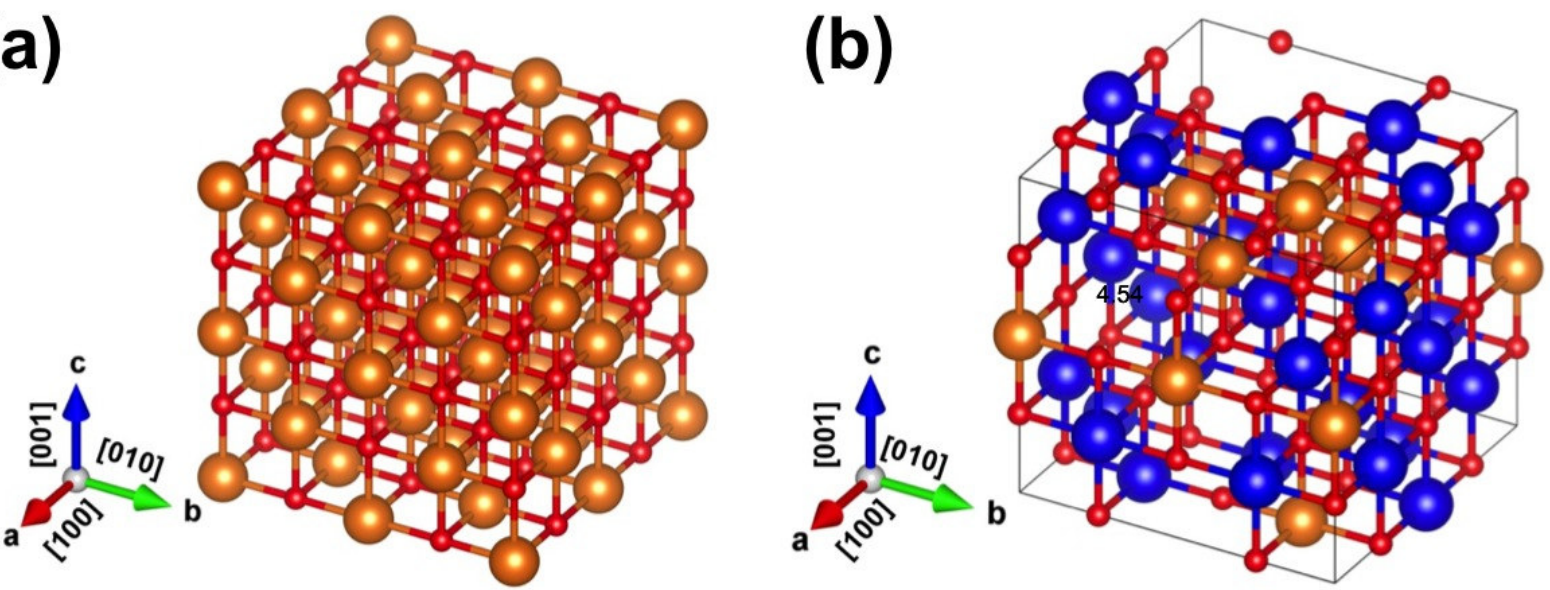

$\odot \mathrm{Mg} \odot \mathrm{O} C \mathrm{Cr}$ or $\mathrm{Fe}$

(c)

(1)

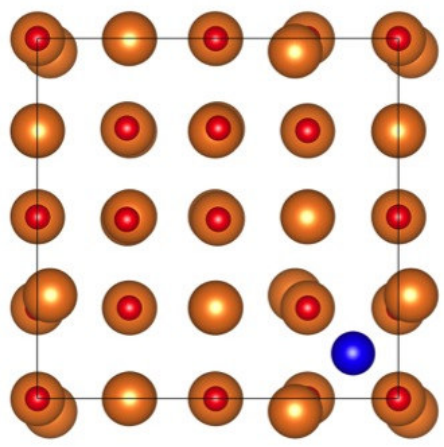

(2)

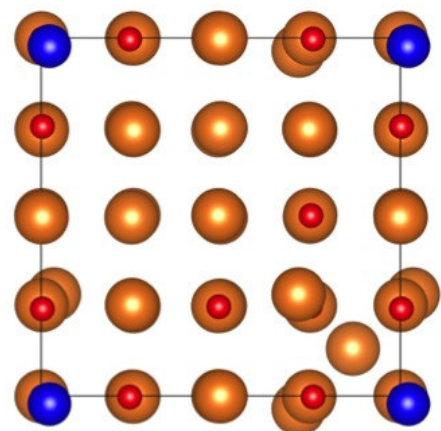

(3)

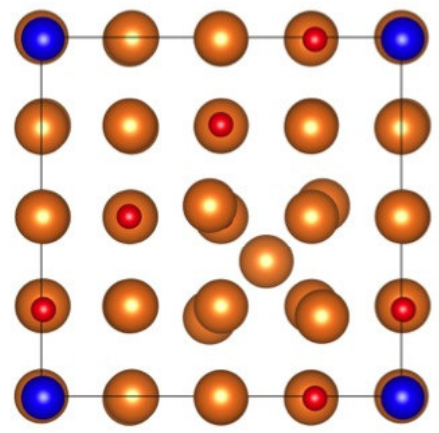

(d)

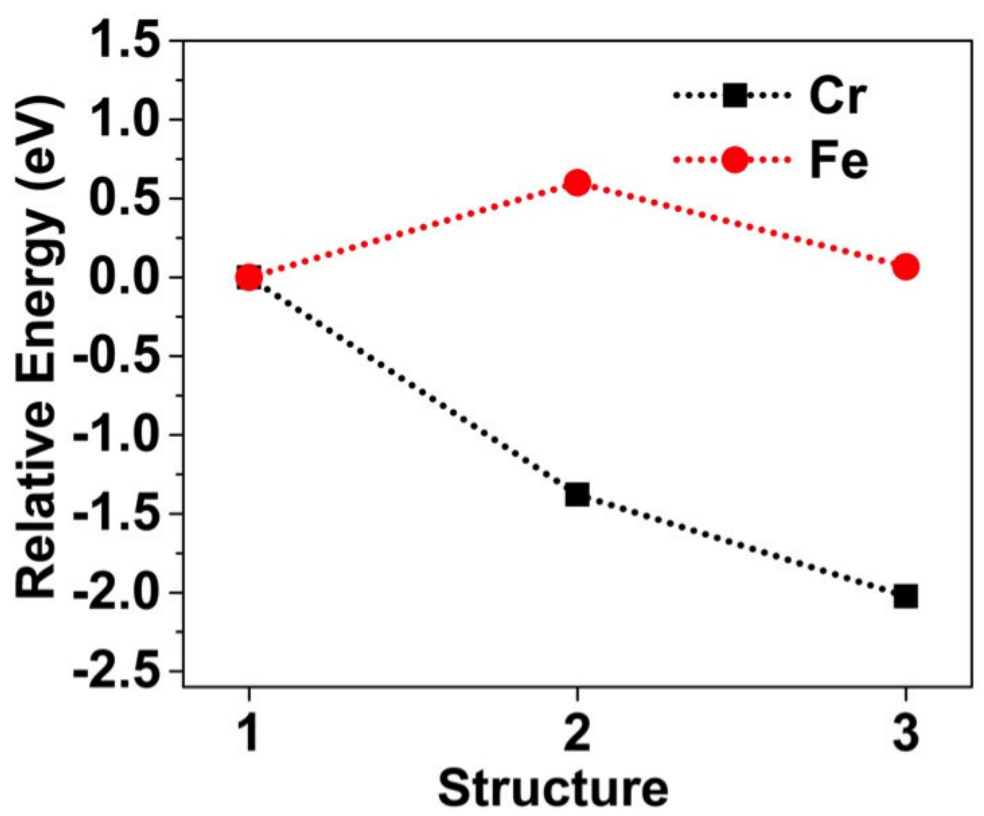

